\title{
Semantic space and encoding space in short-term memory
}

\author{
DAVID G. WEEKS \\ California State University, Fullerton, California 92634
}

\begin{abstract}
Wickens' release from proactive inhibition (PI) technique has been used to identify a number of encoding categories in short-term memory. When repeated presentation of words in one class followed by a shift to words in another class leads to improved recall (PI release), the classes are considered encoding categories. The Osgood semantic dimensions have been effective in producing PI release. These dimensions constitute a continuous semantic space, suggesting a corresponding encoding space with measures of PI release corresponding to distances. Using the Wickens technique, PI release scores were obtained in several regions of semantic space. Subjects were 40 undergraduates. The relation between distances in semantic space and release scores was highly linear, and the encoding space was approximately euclidean. Results suggest that the encoding process can use information from continuous variables in a quantitatively precise way.
\end{abstract}

The release from proactive inhibition (PI) technique developed by Wickens (1970) has been used extensively to identify encoding categories in short-term memory (STM) (Wickens, 1970, 1972, 1973). Using the BrownPeterson paradigm, three trials with words in one class were followed by a fourth trial with words in a different class. Improved recall (PI release) on the shift trial implied that the classes were used as STM encoding categories, on the assumption that improvement in recall was due to differential encoding.

A number of different variables have been investigated with this technique. Most have been categorical, e.g., words to numbers (Reutener, 1972), taxonomic categories (Goggin \& Wickens, 1971), verbs to adjectives (Wickens, Clark, Hill, \& Wittlinger, 1968). Osgood semantic differential dimensions (Osgood, Suci, \& Tannenbaum, 1957) were found effective in producing PI release (Wickens \& Clark, 1968). The opposite ends of these dimensions were used as categories, although they really constitute continuous variables.

Connotative meaning may be represented as a continuous semantic space, and it is used in STM encoding. Thus, it may be more appropriate in this instance to speak of an encoding space, rather than encoding categories. To be a useful conceptualization, encoding space should exhibit certain regularities. Release measures should closely correspond to shift distances in semantic

This research was supported in part by a grant from the DAC, California State University, Fullerton. Portions of this research were presented at the meeting of the Western Psychological Association, Los Angeles, 1976. The author wishes to thank Richard H. Lindley for assistance in all phases of this research, and Thomas D. Wickens, who sponsors this paper and takes full editorial responsibility for its content, for helpful comments on the manuscript. Reprint requests should be sent to David G. Weeks, Department of Psychology, University of California, Los Angeles, 405 Hilgard, Los Angeles, California 90024. space. They should be at least monotonic, and ideally would be linearly related. The direction of shift should not make any difference. The position in the space (e.g., 1 to 2, 2 to 3) also should not affect release scores. The effect of a multidimensional shift should be predictable from the effects of the component unidimensional shifts. It should at least satisfy Equation 1:

$$
\mathrm{x}_{\mathrm{a}}=\left[\sum_{\mathrm{i}}^{\mathrm{M}}\left(\mathrm{x}_{\mathrm{i}} \mathrm{r}\right)\right]^{1 / \mathrm{r}},
$$

where $\mathrm{x}$ is a distance derived from the release score, $\mathrm{x}_{\mathrm{a}}$ is the derived distance for a shift over all $\mathrm{M}$ dimensions, $x_{i}$ is the distance for a shift on dimension $i$ alone, and $r$ is the Minkowski power metric, $r \geqslant 1$. Ideally, $r=2$ for euclidean space. The purpose of this study was to test for these regularities, and thus explore the usefulness of the encoding space conceptualization.

\section{METHOD}

\section{Subjects}

Subjects were 40 introductory psychology students who participated in this experiment as part of a course requirement.

\section{Stimuli}

Nouns taken from the Heise (1965) list were used to form word trigrams located in specific regions of semantic space. A "unidimensional set" was formed from words loading primarily on the potency (P) and activity (A) dimensions. These were used to form three shift-distance conditions $(4,2$, and 0 standard deviations). Within each distance condition were several subconditions relating to direction and place of shift. These are listed in Table 1. A "bidimensional set" was formed from four groups located at the vertices of a rectangle in the E-P plane. The shift conditions for this group (shifts from one vertex to another) were to allow estimation of the effect of a shift on either dimension alone and on both together (see Table 2).

\section{Procedure}

Each subject was instructed in the task and given a practice session. Stimuli were presented on slides in a Carousel projector, 
Table 1

Shift Conditions: Unidimensional Set

\begin{tabular}{|c|c|c|}
\hline Distance & Trials $1-3$ & Trial 4 \\
\hline 4 & $\begin{array}{l}+2 \\
-2\end{array}$ & $\begin{array}{l}-2 \\
+2\end{array}$ \\
\hline 2 & $\begin{array}{l}+1 \\
-1 \\
+.5\end{array}$ & $\begin{array}{l}-1 \\
+1 \\
-1.5\end{array}$ \\
\hline . & $\begin{array}{l}+2 \\
+1 \\
+.5 \\
-.5 \\
-1 \\
-2\end{array}$ & (Same) \\
\hline
\end{tabular}

Table 2

Shift Conditions: Bidimensional Set

\begin{tabular}{lll}
\hline \multirow{2}{*}{$\begin{array}{c}\text { Distance and } \\
\text { Dimension }\end{array}$} & \multicolumn{2}{c}{ Location } \\
\cline { 2 - 3 } $1.2 \mathrm{E}$ & \multicolumn{1}{c}{ Trials $1-3$} & \multicolumn{1}{c}{ Trial 4 } \\
\hline \multirow{2}{*}{$2.1 \mathrm{P}$} & $(0,-1.2)^{*}$ & $(1.2,-1.2)$ \\
& $(0, .9)$ & $(1.2, .9)$ \\
& $(1.2, .9)$ & $(0, .9)$ \\
2.42 Both & $(0,-1.2)$ & $(0, .9)$ \\
& $(1.2, .9)$ & $(1.2,-1.2)$ \\
& $(0, .9)$ & $(1.2,-1.2)$ \\
& $(1.2,-1.2)$ & $(0, .9)$ \\
& $(0,-1.2)$ & $(1.2, .9)$ \\
& $(1.2, .9)$ & $(0,-1.2)$ \\
\hline
\end{tabular}

*In the form (location on E, location on P)

with presentation times controlled by tape. A trial began with a "ready" slide ( $1 \mathrm{sec})$, followed by the words $(2 \mathrm{sec})$, followed by a three-digit number. At the onset of the number, the subject immediately repeated it, and began counting backward by threes from that number. After $20 \mathrm{sec}$, a signal to recall the words was presented. Eight seconds were allowed for recall, after which another trial began. Each block of four triais corresponded to one shift condition. There was a 3-min break between blocks.

Thirty-six subjects received each of the three distance conditions in the unidimensional set; these and four others received two conditions from the bidimensional set. Order of presentation and subcondition assignment were randomized, with the constraint that no subject saw the same word twice.

\section{RESULTS}

The number of words correctly recalled on each trial was tallied, with an additional point counted for correct order of recall for all three words. This score for Trial 3 was subtracted from the score for Trial 4 . This provided a single measure positively related to PI release.

For data from the unidimensional set, separate analyses of variance were done within each distance condition, to test the effects of the subconditions. None was statistically significant. Analysis over the three distance conditions showed a significant effect $[F(2,70)=4.86, p<.05]$, with means at $.78, .22$, and -.28 for the 4,2 , and 0 shifts, respectively. A trend analysis showed over $99 \%$ of the variance accounted for by the linear component $[\mathrm{F}(1,70)=9.62$, $\mathrm{p}<.005]$. This was the only significant trend component.

The data from the bidimensional set were used to estimate the metric of the encoding space. The means from this set were .55 (shift on E), .1 (shift on P), and .75 (shift on both). The mean for the no-shift condition $(-.28)$ was subtracted from each of these means, so that zero distance in semantic space was equated with zero on the PI release measure. These values were substituted into Equation 1, which, when solved for $r$, yielded the value of 1.37 . This is intermediate between the city block $(r=1)$ and euclidean $(r=2)$ metrics; the euclidean metric provided a better fit (deviation from predicted was .18 for $r=1$ and .12 for $r=2$ ). Since only one set of distances was available, a measure of the goodness of fit of the 1.37 value was not available.

\section{DISCUSSION}

The relation between distances in semantic space and PI release scores was highly linear, and differences in duration or place of shift did not produce significant effects. In two dimensions the release scores behaved very much like distances in euclidean space. Evidently the encoding process uses not only categorical information, but also information from continuous variables in a quantitatively precise way. It may be that presentation of the first words initiates a category which includes in its characteristics a notion of the centroid of the category in connotative space. This sort of category is much more flexible than typical semantic and linguistic categories. It is entirely compatible with a representation in euclidean space.

The metric of encoding and semantic spaces, in general, is an empirical question. The stimuli used to produce PI release scores were already well represented in a euclidean space. Similarly, Rips, Shoben, and Smith (1973) achieved a good fit to rated similarities of words with a (euclidean) multidimensional scaling procedure. The recovered distances between instances of a class (e.g., chicken) and the class name (bird) were highly correlated with times to confirm set relations. For other semantic relations, particularly among different and ill-defined sets, the metric may well be non-euclidean. In such cases, proximity related measures of cognition (such as PI release scores) may also be best described by a non-euclidean metric. Alternately, the stimuli may be represented by a euclidean metric when scaled from similarity ratings, but a particular measure may produce values resembling distances generated by a different metric in the same space. When it is possible to scale the stimuli in some psychological space and find a rational relation between the configuration and measures of a cognitive process, then the validity of both the psychological space and a model of the process are supported.

\section{REFERENCES}

Goggin, J., \& Wickens, D. D. Proactive interference and language change in short-term memory. Journal of Verbal Learning and Verbal Behavior, 1971, 10, 453-458.

Heise, D. R. Semantic differential profiles for 1000 most frequent English words. Psychological Monographs, 1965, 79(8, Whole No. 601). 
Osgood, C. E., Suci, G. J., \& Tannenbaum, P. H. The measurement of meaning. Urbana: University of Illinois Press, 1957.

Reutener, D. B. Class shift, symbolic shift, and background shift in short-term memory. Joumal of Experimental Psychology, 1972, 93, 90-94.

Rips, L. J., Shoben, E. J., \& Smith, E. E. Semantic distance and the verification of semantic relations. Journal of Verbal Learning and Verbal Behavior, 1973, 12, 1-20.

WiCKens. D. D. Encoding characteristics of words: An empirical approach to meaning. Psychological Review. 1970, 77, 1-15.

WiCkens. D. D. Characteristics of word encoding. In A. W.
Melton \& E. Martin (Eds.). Coding processes in human memory. Washington, D.C: Winston, 1972.

Wickens, D. D. Some characteristics of word encoding. Memory \& Cognition, 1973, 1, 485-490.

Wickens, D. D., \& Clark, S. E. Osgood dimensions as an encoding category in short-term memory. Journal of Experimental Psychology, 1968, 78, 580-584.

Wickens, D. D., Clark, S. E., Hill, F. A., \& Wittlinger, R. P. Grammatical class as an encoding category in short-term memory. Journal of Experimental Psychology, 1968, 78, 599-604.

(Received for publication July 11, 1976.) 